\title{
A proposed adaptation of the European Foundation for Quality Management Excellence Model to physical activity programmes for the elderly - development of a quality self- assessment tool using a modified Delphi process
}

Ana I Marques ${ }^{1 *}$, Leonel Santos ${ }^{2}$, Pedro Soares ${ }^{3}$, Rute Santos ${ }^{1,4}$, António Oliveira-Tavares ${ }^{1}$, Jorge Mota ${ }^{1}$ and Joana Carvalho'

\begin{abstract}
Background: There has been a growing concern in designing physical activity (PA) programmes for elderly people, since evidence suggests that such health promotion interventions may reduce the deleterious effects of the ageing process. Complete programme evaluations are a necessary prerequisite to continuous quality improvements. Being able to refine, adapt and create tools that are suited to the realities and contexts of PA programmes for the elderly in order to support its continuous improvement is, therefore, crucial. Thus, the aim of this study was to develop a self-assessment tool for PA programmes for the elderly.

Methods: A 3-round Delphi process was conducted via the Internet with 43 national experts in PA for the elderly, management and delivery of PA programmes for the elderly, sports management, quality management and gerontology, asking experts to identify the propositions that they considered relevant for inclusion in the selfassessment tool. Experts reviewed a list of proposed statements, based on the criteria and sub-criteria from the European Foundation for Quality Management Excellence Model (EFQM) and PA guidelines for older adults and rated each proposition from 1 to 8 (disagree to agree) and modified and/or added propositions. Propositions receiving either bottom or top scores of greater than $70 \%$ were considered to have achieved consensus to drop or retain, respectively.
\end{abstract}

Results: In round 1, of the 196 originally-proposed statements (best practice principles), the experts modified 41, added 1 and achieved consensus on 93. In round 2, a total of 104 propositions were presented, of which experts modified 39 and achieved consensus on 53. In the last round, of 51 proposed statements, the experts achieved consensus on 19. After 3 rounds of rating, experts had not achieved consensus on 32 propositions. The resulting tool consisted of 165 statements that assess nine management areas involved in the development of PA programmes for the elderly.

Conclusion: Based on experts' opinions, a self-assessment tool was found in order to access quality of PA programmes for the elderly. Information obtained with evaluations would be useful to organizations seeking to improve their services, customer satisfaction and, consequently, adherence to PA programmes, targeting the ageing population.

Keywords: physical activity, programmes, elderly, tool, evaluation, quality, adherence

\footnotetext{
* Correspondence: anavalente@netvisao.pt

${ }^{1}$ Research Centre in Physical Activity, Health and Leisure, Faculty of Sports,

University of Porto, Porto, Portugal

Full list of author information is available at the end of the article
} 


\section{Background}

Physical activity (PA) programmes play a significant role in senior citizens' health, autonomy and ability to face daily tasks, being particularly important to prevent and minimize the deleterious effects of the ageing process $[1,2]$ and to improve quality of life [1-4]. It is widely accepted that the benefits of such programmes depend on adherence to exercise, which is influenced by degree of enjoyment and satisfaction [5-10]. One of the most important factors in customer satisfaction is quality of service [11-13]. Therefore, continual improvements in PA programmes for the elderly are important to elderly satisfaction and adherence to PA.

The $3^{\text {rd }}$ Benchmark from the Physical Activity and Health Branch of the Centers for Disease Control and Prevention (CDC) [14] holds that complete programme evaluations are an important and desired prerequisite to continuous quality improvements. Similarly, World Health Organization (WHO) guidelines for the evaluation of health promotion emphasize the need to evaluate and propose the allocation of adequate evaluative resources [15].

Evidence shows that quality matters, is measurable, moveable and malleable [16], but also has costs [17]. However, literature also shows that the costs of not doing so are far greater $[18,19]$. Several studies have focused on the advantages of quality schemes [20-22]. With the aim of helping organizations improve the quality of their services, the European Foundation for Quality Management (EFQM) introduced the EFQM Excellence Model in 1991. The EFQM Excellence Model is a non-prescriptive framework that is based on nine criteria divided into 32 sub-criteria [13]. It promotes the use of management methodologies based on objective criteria that are applicable to all areas of business or services and constitutes an exercise in self-assessment. Selfassessment sheds light on areas requiring improvement, as well as on the processes and actions necessary to generate improvement.

While numerous PA programmes have been designed for the elderly in recent years - especially by the Public Local Administration - their evaluation has been scarce. In fact, few details are available on how these programmes have been developed, how they have been structured, how service delivery is conducted and how results are being achieved. The lack of a standard approach to assessing PA programmes for the elderly makes it difficult to compare the quality of both the planning and the delivery of such programmes. In this way, being able to refine, adapt and create tools that are suited to the realities and contexts of PA programmes for the elderly, and that improve these programmes, is therefore important, not only to help programmes evaluate their ability to perform public health functions, but to address local health needs and guide community health-planning efforts. Thus, the aim of this study is to describe the development of a quality self-assessment tool for PA programmes for the elderly.

\section{Methods}

A modified Delphi process was conducted using the Internet, from October 2009 to September 2010. The Delphi technique was developed in the 1950 s by scientists at the Rand Corporation as a method of making informed decisions based on expert opinion [23]. Since then, it has been used to clarify a variety of problems in different sectors [24-29]. Despite having undergone some modifications, it remains a viable approach for gathering expert opinions through a structured iterative process that builds consensus [30]. This process involves multiple interactions with participants who usually complete two or more rounds in a reasonable amount of time [31] - even when participants are in geographically-distinct locations, since rounds can be conducted by mail or email $[32,33]$. The results of previous iterations can be modified by participants in later iterations, as they are able to review comments and feedbacks provided by other experts in earlier rounds [31]. Furthermore, the Delphi technique offers a number of specific advantages and is particularly helpful because it avoids the barriers commonly observed in other group discussions, such as interpersonal influence, time pressure and group demands $[31,34,35]$. This is due to the fact that respondents are not aware of the identities of other respondents and are, therefore, freed of personal and social constraints [30]. They are also able to complete the Delphi rounds in ways that suit them best because they participate in the rounds asynchronously [36]. The Delphi technique is also advantageous because a variety of statistical analysis techniques can be used to interpret the data its generates [37].

The Delphi process was conducted in three rounds [38,39] (Figure 1). Following each step listed in the previous figure, our main question was: Which quality practices must be included in a quality self-assessment tool for PA programmes for the elderly?

Using criteria and sub-criteria from the EFQM Excellence Model [13] and PA guidelines for older adults $[3,40]$ as a starting point, we reviewed the literature to identify best practice principles and generate a list of statements. Our review was undertaken using PubMed (1980-2010), B-On (1980-2010), and Google ${ }^{\mathrm{TM}}$. We searched a variety of combinations of key words related to PA programmes for the elderly, quality management and the EFQM Excellence Model, such as: 'evaluation', 'guidelines', 'recommendations', 'exercise', 'physical 


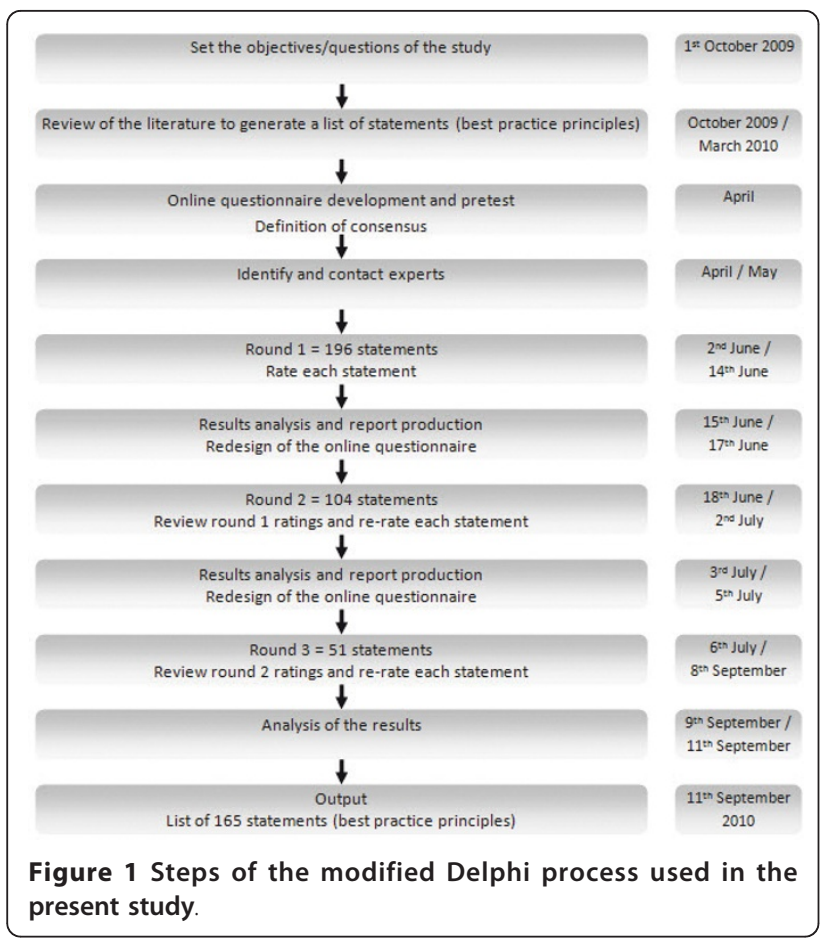

activity', 'programmes', 'elderly', 'old', 'review', 'framework', 'EFQM', 'assess' and 'quality'.

After identifying a list of statements, an online questionnaire was developed and tested with 5 PA programme coordinators for comments on readability and functionality. Some adjustments were made to make the affirmations included in the questionnaire clearer and more relevant to this case. We established that statements that received greater than $70 \%$ of experts' votes had achieved consensus [41-43] in both the bottom scores (i.e., reached consensus to drop) and top scores (i.e., reached consensus to include/retain). Statements that were dropped were not included in subsequent rounds of ratings. The remaining items were included in the next rounds, until a consensus was achieved to either drop or retain. At the end of three rounds, the statements on which experts had not reached consensus were also not included in the output list.

The fourth phase of the process involved nominating experts to participate in the Delphi rounds. National experts in research on PA for the elderly, PA programmes for elderly management and delivery, sports management, quality management and gerontology were identified. Our decisions were based on expertise or/and breadth of scientific work [44]. The DeGóis Curricula Platform ${ }^{1}$ assisted us in this process. A list of 63 potential participants was generated, along with key contacts for each. This group included $34 \mathrm{PhD}$ scientists and academics (11 in PA for the elderly, 4 in sports management, 18 in quality management and 1 in gerontology),
3 non-PhD academics ( 1 in PA for the elderly and 2 in sports management) and 26 senior technicians (22 in PA programmes for elderly management and delivery, 3 in quality management and 1 in gerontology). Previous information containing details about the EFQM Excellence Model, the Delphi process and the purpose of our study was provided. Of those invited to participate, 5 did not respond and 3 declined, due to lack of time (all $\mathrm{PhD}$ scientists and academics in quality management). Thus, 55 experts ( 30 females and 25 males) responded to our initial invitation and agreed to participate. Those who accepted our invitation were informed that they were required to respond to three online rounds of ratings.

The rounds were performed using Survey Monkey, a web-based survey and data collection system. In every round, participants were asked to rate their level of agreement with each proposition, from 1 to 8 ('strongly disagree' to 'strongly agree'), suggest modifications to proposed definitions and/or add propositions that would be useful in a quality self-assessment tool for PA programmes for the elderly. The 8-point Likert scale was selected to bring out more variability in responses [45]. After each round, the frequency and mean of the panel's ratings and the percentage of scores $\geq 7$ were calculated. Based on this data, a new questionnaire was designed and placed online for the next round. We asked participants to review all the information sent and re-rate each statement.

After round 3, we gathered all our data and developed a list of statements that did and did not reach consensus.

\section{Results}

Eight of the 63 invited experts, did not respond or declined. Of the 55 who agreed to participate in this process, 43 responded to round 1 and were invited to participate in the subsequent rounds. This group included 25 females and 18 males and was comprised of $20 \mathrm{PhD}$ scientists and academics (9 in PA for the elderly, 2 in sports management, 8 in quality management and 1 in gerontology), 2 non- $\mathrm{PhD}$ academics ( 1 in PA for the elderly and 1 in sports management) and 21 senior technicians (17 in PA programmes for elderly management and delivery, 3 in quality management and 1 in gerontology). The 12 experts who did not respond to round 1 were not involved in subsequent rounds.

The results of the three rounds (total number of statements, statements approved by consensus, statements without consensus, statements modified by experts and new statements proposed by experts) for the nine criteria are presented in Table 1.

In round 1, of the 196 originally-proposed statements (best practice principles), the experts modified 41, added 
Table 1 Results of the three rounds by criterion

\begin{tabular}{|c|c|c|c|c|c|c|c|c|c|c|c|}
\hline & & LEADERSHIP & $\begin{array}{l}\text { POLICY \& } \\
\text { STRATEGY }\end{array}$ & PEOPLE & $\begin{array}{c}\text { PARTNERSHIP \& } \\
\text { RESOURCES }\end{array}$ & PROCESSES & $\begin{array}{l}\text { CUSTOMER } \\
\text { RESULTS }\end{array}$ & $\begin{array}{l}\text { PEOPLE } \\
\text { RESULTS }\end{array}$ & $\begin{array}{l}\text { SOCIETY } \\
\text { RESULTS }\end{array}$ & $\begin{array}{c}\text { KEY PERFORMANCE } \\
\text { RESULTS } \\
\end{array}$ & TOTALS \\
\hline \multirow[t]{5}{*}{$1^{\text {st }}$ ROUND } & With consensus & 13 & 12 & 18 & 15 & 27 & 3 & 3 & 1 & 1 & 93 \\
\hline & Without consensus & 9 & 7 & 12 & 11 & 13 & 2 & 5 & 2 & 1 & 62 \\
\hline & To modify & 14 & 9 & 7 & 0 & 7 & 1 & 1 & 0 & 2 & 41 \\
\hline & To add & 0 & 0 & 1 & 0 & 0 & 0 & 0 & 0 & 0 & 1 \\
\hline & Total & 36 & 28 & 37 & 26 & 47 & 6 & 9 & 3 & 4 & 196 \\
\hline \multirow[t]{5}{*}{$2^{\text {nd }}$ ROUND } & With consensus & 14 & 5 & 14 & 2 & 12 & 2 & 2 & 0 & 2 & 53 \\
\hline & Without consensus & 8 & 8 & 4 & 6 & 5 & 1 & 4 & 2 & 1 & 39 \\
\hline & To modify & 1 & 3 & 2 & 3 & 3 & 0 & 0 & 0 & 0 & 12 \\
\hline & To add & 0 & 0 & 0 & 0 & 0 & 0 & 0 & 0 & 0 & 0 \\
\hline & Total & 23 & 16 & 20 & 11 & 20 & 3 & 6 & 2 & 3 & 104 \\
\hline \multirow[t]{3}{*}{$3^{\text {rd }}$ ROUND } & With consensus & 2 & 5 & 2 & 4 & 4 & 1 & 0 & 1 & 0 & 19 \\
\hline & Without consensus & 7 & 6 & 4 & 5 & 4 & 0 & 4 & 1 & 1 & 32 \\
\hline & Total & 9 & 11 & 6 & 9 & 8 & 1 & 4 & 2 & 1 & 51 \\
\hline
\end{tabular}


1 and achieved consensus on 93, which were retained for inclusion in the self-assessment tool. Of the 41 suggested modifications, 14 were related to Leadership (38,39\%), 9 to Policy \& strategy $(32,14 \%), 7$ to People (18,92\%), 7 to Processes $(14,89 \%), 1$ to Customer results and People results (16,67\% and 11,11 respectively) and 2 to Key performance results (50\%). Some modifications consisted of minor changes to words or sentence structures, while others were about content (e.g., change "Higher education qualification, with specialization in physical activity and aging, is required for instructors'/ teachers' programmes" to "Higher education qualification, with specialization in physical activity and aging, or relevant experience in this field, is required for instructors'/teachers' programmes". The addition was related to the People criterion. Generally, experts made the greatest number of suggestions to Leadership and the fewest (0 in this case) to Partnership \& resources and Society results. The best practice principles that were retained were mostly in Partnership \& resources (15 out of 26, i. e. $57,69 \%$ ), Processes (27 out of 47 , i.e. $57,45 \%$ ) and Customer results ( 3 out of 6 , i.e. $50 \%$ ). The criterion on which least consensus was reached was Key performance results ( 1 out of 4 , i.e. $25 \%$ ). No proposition was dropped in round 1, i.e. none received greater than $70 \%$ of the experts' votes in both the bottom scores.

Based on the results of round 1, 104 propositions were presented in round 2. At this stage, experts modified 39 and achieved consensus on 53 propositions. Most of the suggestions were made on Policy \& strategy, Partnership $\&$ resources and Processes, with none suggestions to Results' criteria. The best practice principles that were retained were mostly in People (14 out of 20, i.e. $70 \%$ ), Leadership (14 out of 23, i.e. 60,87\%) and Processes (12 out of 20 , i.e. $60 \%$ ). The criterion on which there was least consensus was Society results, on which there was no agreement. Once more, no proposition was dropped. Forty one of the 43 experts responded to round 2 .

In the last round, of the 51 statements proposed, the experts achieved consensus on 19, mostly in Policy \& strategy (5 out of 11 , i.e. $45,45 \%$ ), Processes (4 out of 8 , i.e. 50\%) and Partnership \& resources (4 out of 9, i.e. $44,44 \%)$. After 3 rounds of rating, they had not achieved consensus on 32 propositions. Most of these statements were concerned with Leadership (7, i.e. 21,88\%), Policy \& strategy (6, i.e. $18,75 \%)$ and Partnership \& resources (5, i.e. $15,63 \%)$. One expert who had not responded to round 2 was willing to participate in round 3 ; thus, 42 of the 43 experts responded to round 3 .

Additional file 1 presents the resulting tool - named Q-STEPS (Quality Self-assessment Tool for Exercise Programmes for Seniors) - which consists of 165 statements that assess nine areas involved in the development of PA programmes for the elderly. Five criteria assess Enablers (Leadership, Policy \& strategy, People, Partnership \& resources, and Processes) and four criteria assess the Results (Customer results, People results, Society results, and Key performance results).

\section{Discussion}

The main goal of this study was to describe the development of a quality self-assessment tool for PA programmes for the elderly. To the best of our knowledge, no previous studies have sought expert opinions on PA for the elderly, PA programmes for elderly management and delivery, sports management, quality management and gerontology, with the aim of identifying practices that must be observed when assessing the quality of such programmes.

Although there are recommendations and guidelines for promoting the physical activity of older people $[3,40]$ and recommendations about the need to evaluate these interventions [14,46], the literature is scarce [47], if not absent, on how to integrate these recommendations into PA programmes. No framework or tool has yet been developed to identify or influence the enablers and outcomes of PA programmes for the elderly.

The 43 national experts who participated in the Delphi process were quite engaged throughout, as evidenced by the number of their suggestions (one addition and 53 modifications) and the greater than $97 \%$ response rate to all three rounds of ratings. Most of their suggestions pertained to Leadership, while they made no suggestions on Society results. We presume that these results are related to the fact that many experts are programme leaders and thus, are more aware of practices that pertain to Leadership. Also, experts may have been aware of the fact that Leadership is understood by some authors [48-50] as the key to driving quality improvement. Our data indicate a high degree of consensus on the retention of all propositions concerning the development of vision and mission and the enhancement of a culture of communication by programme coordinators. These are considered fundamental to quality management [51-53], since the physical presence of leaders - their visibility and concern for quality improvement - are associated with transformational leadership [54], i.e. leadership that creates valuable and positive change in its followers. Of the seven statements on Leadership on which experts did not achieve consensus, five belong to the sub-criteria that concern the interaction of programme coordinators with politicians, customers, partners and representatives of society. While our study revealed that most of the statements concerning interaction with customers, partners and representatives of society achieved consensus, propositions concerning relationships with politicians or political affairs did not achieve consensus. This may be 
related to popular negative perceptions of the political class [55]. Examples of statements that touched on the relationship between leadership and politics include "The coordinator manages relations with politicians and other stakeholders to ensure shared responsibility" and "The coordinator interacts regularly and proactively with policy makers from relevant executive areas (e.g. Alderman of Sport)". The British Heart Foundation (BHF) has stated that participants or other stakeholders must be actively involved in all aspects of programme development, including planning, promotion and evaluation [40]. The ACSM also recognizes that PA leaders should work closely with individuals to design PA regimens that reflect personal preferences and capabilities [56].

Leaders unanimously agreed to retain statements about the importance of leaders identifying and championing organizational change. Fostering change is increasingly seen as part of a leader's role [57], and the EFQM Fundamental Concepts upon which the Model is based [58] include standard recommendations such as planning change, communicating reasons for it, enabling people to manage change and reviewing the effectiveness of change.

Experts also suggested modifications to about $30 \%$ of the original propositions on Policy \& strategy. A high degree of consensus was achieved on the retention of all propositions concerning the development, review and updating of policy and strategy.

The statement that received the greatest degree of consensus was related to the development of annual reports. Data from such reports helps improve the annual planning cycles of PA programmes. These procedures are in agreement with those found in other studies $[59,60]$ or with different documents, such as those that outline the planning and evaluation of PA programmes $[61,62]$ and health promotion programmes [63].

Throughout the Delphi process, it was suggested that the proposition "The programme involves a multidisciplinary team of professionals" be added to the People criterion. In fact, the teams that run PA programmes for seniors should include not only exercise and sports professionals, but general practitioners, practice nurses and care and residential managers [40]. Of the propositions on the planning, management and improvement of human resources that the experts agreed to retain, the one on which there was greatest consensus was "Emphasis is placed on recruiting employees whose profile matches the needs of the programme". The Physical Activity and Health Branch (PAHB) of the CDC has established that PA programmes should be run by highly-skilled PA practitioners [14]. The Cross-National Expert Survey Report on Physical Activity Programmes and Physical Activity Promotion Strategies for Older People [64] also notes the importance of recruiting teachers who are highly qualified and reinforces the importance of continuous professional development.

During the first round, a high level of consensus was immediately reached on propositions related to the management of finances and maintenance of facilities, equipment and materials (Partnership \& resources criterion). The management of financial resources is key to consolidating programmes' financial structure and ensuring that programmes can fulfil their missions in the present and the future, as well as periodically provide maintenance plans for equipment and buildings $[65,66]$. Experts did not achieve consensus on half the propositions concerning "external partnerships", although the development and sustainment of community partnerships is the first public health benchmark for PA programmes established by the PAHB [14]. Particularly with regards to PA programmes for the elderly, some organizations have reinforced the importance and strength of these partnerships, which provide additional resources in the form of funding, facilities and equipment, as well as access to wide-ranging abilities and knowledge $[40,67]$. Indeed, one of the propositions that did not reach consensus was the one that pointed the participation in networks in order to exchange knowledge and to improve relationships. However, of the propositions on which experts did not achieve consensus, most were similar to other statements that were retained. Examples include: "Appropriate partnership agreements are established, defining roles, responsibilities and expected outcomes" and "Regular and formal communication procedures are established with partners".

Consensus was not reached on only four of the 47 statements about Processes. Once more, most were similar to other statements that were retained. For example, "Market research is used to determine the needs and expectations of future customers" - a proposition that only received $64,29 \%$ of votes equal to or greater than 7 - is comparable to "Surveys and other ways of obtaining feedback are used to determine the needs and expectations of current and future customers", a retained proposition. Physical activity leaders should work closely with individuals to design PA regimens that reflect personal preferences and capabilities [56]. The BHF recommends that participants should be involved in this process [40]. Moreover, tailoring exercise programmes to the needs and interests of participants has been associated with higher programme attendance $[68,69]$.

Concerning the four Results' criteria, the highest level of consensus was achieved on Customer results, in which all propositions were accepted. Indeed, organizations must measure and achieve customer results [13]. 
Similarly, both the processes by which PA interventions are conducted and the outcomes of such interventions should be evaluated [47]. The experts achieved a high degree of consensus on all propositions related to client assessment, i.e. customer satisfaction, customer loyalty, communication, complaints handling and management and outcomes (physical fitness evaluations and psychological/mental evaluations). By contrast, they displayed relatively little consensus on the criterion People results (4 out of 9). In fact, the experts were unable to reach consensus on whether or not to retain propositions related to employee involvement, motivation, initiative and loyalty. However, it should be emphasised that similar statements were retained. Examples include: "The programme has measures of perception and/or performance indicators regarding employees' performance" and "The programme has measures of perception and/ or performance indicators regarding employees' involvement in teamwork". In actuality, to achieve excellence, organisations must also focus on People results [13], since employee involvement is one of the most important drivers of continuous improvement [58]. Furthermore, without satisfied and motivated employees, it is impossible to create satisfied and loyal customers [70].

The tool that resulted from this process provides a framework tailored to evaluating PA programmes for the elderly, applicable to a variety of settings, namely community-based programmes and/or those developed by the Public Local Administration. The information obtained through such evaluations would be useful for organizations seeking to improve their services. It would help them guide interventions toward excellence, in order to improve customer satisfaction and adherence to PA programmes targeting the ageing population.

\section{Strengths and Limitations}

To the best of our knowledge, this is the first study to gather expert opinions with the aim of identifying practices that must be observed when assessing the quality of PA programmes for the elderly. Because of the heterogeneity of their interests, panel members were able to cover a broad range of topics. In addition, they were able to submit comments on each sub-criterion in every round, enabling us to use their expertise to develop or modify new statements. This also guaranteed that the process did not neglect to include any pertinent issues in subsequent rounds of rating.

However, this study has certain limitations. Our results should not be interpreted as representing the views of all experts in the field of quality management, physical activity for older adults or gerontology, due to the process used to collect the sample. It is also important to note that the tool suggested by our consensus process may not be applicable to certain PA programmes, including those for special population subgroups, such as: the most elderly, the frail, older adults with chronic illnesses or varying degrees of medical comorbidity. Likewise, our consensus-informed quality practices do not reflect possible differences in PA programmes that were developed in institutional elderly care settings. Additional research is necessary to provide the feasibility analysis of this assessment and to adapt and replicate our tool to other circumstances.

\section{Conclusion}

Our Delphi process identified 165 quality practices that 43 experts consider essential to assessments of the quality of PA programmes for the elderly. The Q-STEPS (Quality Self-assessment Tool for Exercise Programmes for Seniors) tool assesses nine areas involved in the development of PA programmes for the elderly: five criteria assess Enablers (Leadership, Policy \& strategy, People, Partnership \& resources, and Processes) and four criteria assess the Results (Customer results, People results, Society results, and Key performance results).

\section{Ethics approval}

The study was approved by the Scientific Council and Ethics Committee of the Faculty of Sport - University of Porto.

\section{Endnotes}

${ }^{1}$ It is an instrument for gathering, supplying and analyze the intellectual and scientific production of the Portuguese researchers.

\section{Additional material}

Additional file 1: Q-STEPS (Quality Self-assessment Tool for Exercise Programmes for Seniors). the file presents the resulting tool-named Q-STEPS - which consists of 165 statements that assess nine areas involved in the development of PA programmes for the elderly.

\section{Acknowledgements}

We would like to thank all the panel members for their time and contributions to this research. This study was supported by FCT - SFRH/BD/ 36796/2007.

\section{Author details}

${ }^{1}$ Research Centre in Physical Activity, Health and Leisure, Faculty of Sports, University of Porto, Porto, Portugal. 'Department of Information Systems, University of Minho, Guimarães, Portugal. ${ }^{3}$ Department of Physical Education, Escola Secundária José Estêvão, Aveiro, Portugal. ${ }^{4}$ Research Centre in Sports, Health Sciences and Human Development, Higher Institute of Maia, Maia, Portugal.

\section{Authors' contributions}

AIM, LS, PS, and JM conceptualized and contributed to the design of this study. AlM participated in the acquisition and analysis of data and participated in drafting and editing the manuscript. AOT and RS managed the data collection and analysis. JC participated in the coordination of the 
study and supervised the drafting and editing of manuscript. All authors reviewed and revised drafts of the manuscript. All authors read and approved the final manuscript.

\section{Competing interests}

The authors declare that they have no competing interests.

Received: 23 March 2011 Accepted: 29 September 2011 Published: 29 September 2011

\section{References}

1. Nelson ME, Rejeski WJ, Blair SN, Duncan PW, Judge JO, King AC, Macera CA Castaneda-Sceppa C: Physical activity and public health in older adults: recommendation from the American College of Sports Medicine and the American Heart Association. Med Sci Sports Exerc 2007, 39(8):1435-1445.

2. Castillo-Garzon MJ, Ruiz JR, Ortega FB, Gutierrez A: Anti-aging therapy through fitness enhancement. Clin Interv Aging 2006, 1(3):213-220.

3. Chodzko-Zajko WJ, Proctor DN, Fiatarone Singh MA, Minson CT, Nigg CR, Salem GJ, Skinner JS: American College of Sports Medicine position stand. Exercise and physical activity for older adults. Med Sci Sports Exerc 2009, 41(7):1510-1530

4. CESEP: Implications of demographic ageing in the enlarged EU. In the domains of quality of life, health promotion and health care. BRUXELLES; 2005.

5. Schutzer KA, Graves BS: Barriers and motivations to exercise in older adults. Prev Med 2004, 39(5):1056-1061.

6. Finch H: Physical Activity 'At Our Age'. Qualitative Research Among People over the Age of 50 London: Health Education Authority; 1997.

7. Wininger SR, Pargman D: Assessment of factors associated with exercise enjoyment. J Music Ther 2003, 40(1):57-73.

8. Henderson KA, Ainsworth BE: Enjoyment: A Link to Physical Activity, Leisure, and Health. Journal of Park and Recreation Administration 2002, 20(4):130-146.

9. Wankel LM: The importance of enjoyment to adherence and psychological benefits from physical activity. Int I Sport Psychol 1993, 24:151-169.

10. Williams NH, Hendry M, France B, Lewis R, Wilkinson C: Effectiveness of exercise-referral schemes to promote physical activity in adults: systematic review. Br J Gen Pract 2007, 57(545):979-986.

11. Parasuraman A, ZeithamI VA, Berry LL: Reassessment of Expectations as a Comparison Standard in Measuring Service Quality: Implications for Further Research. Journal of Marketing 1994, 58(1):111-124.

12. Taylor SA, Baker TL: An Assessment of the Relationship between Service Quality and Customer Satisfaction in the Formation of Consumers' Purchase Intentions. J Retail 1994, 70(2):163-178.

13. EFQM: Introducing Excellence Brussels: European Foundation for Quality Management; 2003.

14. Levin Martin S, Vehige T: Establishing public health benchmarks for physical activity programs. Prev Chronic Dis 2006, 3(3):A110.

15. WHO: Health promotion evaluation: recommendations to policy makers. Report of the WHO European Working Group on Health Promotion Evaluation. World Health Organization Europe; 1999.

16. Eccles J, Gootman J: Quality: building the evidence base. In Forum Focus. Volume 1. Washington, DC: The Forum for Youth Investment, Impact Strategies, Inc; 2003:1-7[http://www.forumforyouthinvestment.org], July/ August edition [Accessed 10 May 2010].

17. Pieper R, Frommelt M, Heislbetz C, Vaarama M: Quality Management in Long-Term Care. In Care-related quality of life in old age: concepts, models, and empirical findings. Edited by: Vaarama M, Pieper R, Sixsmith A. New York: Springer Science+Business Media; 2008:125-150

18. Sakurai M: Gerenciamento Integrado de Custos São Paulo: Atlas; 1997.

19. Morse WJ: Measuring quality costs. Cost and Management 1983, 16-20, July-August.

20. Minkman M, Ahaus K, Huijsman R: Performance improvement based on integrated quality management models: what evidence do we have? A systematic literature review. International Journal for Quality in Health Care 2007, 19(2):90-104

21. Robinson L: Committed to quality: the use of quality schemes in UK public leisure services. Managing Service Quality 2003, 13(3):247-255.

22. Severance $\mathrm{JH}$ : Community health program evaluation using accreditation as a framework. Evaluation \& the health professions 2009, 32(1):59-68.
23. Cornish E: The study of the future: an introduction to the art and science of understanding and shaping tomorrow's world Maryland: World Future Society; 1977.

24. Kelly CM, Jorm AF, Kitchener BA: Development of mental health first aid guidelines on how a member of the public can support a person affected by a traumatic event: a Delphi study. BMC Psychiatry 2010, 10:49.

25. Lieff SJ: Evolving curriculum design: a novel framework for continuous, timely, and relevant curriculum adaptation in faculty development. Acad Med 2009, 84(1):127-134.

26. Tran D, Hall LM, Davis A, Landry MD, Burnett D, Berg K, Jaglal S: Identification of recruitment and retention strategies for rehabilitation professionals in Ontario, Canada: results from expert panels. BMC Health Serv Res 2008, 8:249.

27. Vandelanotte C, Dwyer T, Van Itallie A, Hanley C, Mummery WK: The development of an internet-based outpatient cardiac rehabilitation intervention: a Delphi study. BMC Cardiovasc Disord 2010, 10:27.

28. van Stralen MM, Lechner L, Mudde AN, de Vries H, Bolman C: Determinants of awareness, initiation and maintenance of physical activity among the over-fifties: a Delphi study. Health Educ Res 2010 25(2):233-247.

29. Gupta UG, Clarke RE: Theory and applications of the Delphi technique: A bibliography (1975-1994). Technological Forecasting and Social Change 1996, 53(2):185-211.

30. de Villiers MR, de Villiers PJ, Kent AP: The Delphi technique in health sciences education research. Med Teach 2005, 27(7):639-643.

31. Hsu C-C, Sandford BA: The Delphi technique: making sense of consensus. Practical Assessment Research \& Evaluation 2007, 12[http://pareonline.net/ getvn.asp?v=12\&n=10], [Accessed 25 November 2009].

32. Snyder-Halpern R, Thompson C, Schaffer J: Comparison of mailed vs. internet applications of the Delphi technique in clinical informatics research. In AMIA Symposium: 2000 Edited by: Symposium P-A 2000, 809-813.

33. Landeta J: Current validity of the Delphi method in social sciences. Technological Forecasting and Social Change 2006, 73(5):467-482.

34. Hasson F, Keeney S, McKenna H: Research guidelines for the Delphi survey technique. J Adv Nurs 2000, 32(4):1008-1015.

35. Dalkey NC, Rourke DL: Experimental assessment of Delphi procedures with group value judgments. In Studies in the quality of life: Delphi and decision-making. Edited by: Dalkey NC, Rourke DL, Lewis R, Snyder D. Lexington, MA: Lexington Books; 1972:55-83.

36. Bowles KH, Holmes JH, Naylor MD, Liberatore M, Nydick R: Expert Consensus for Discharge Referral Decisions Using Online Delphi. Biomedical and Health Informatics: From Foundations to Applications: 2003; Washington, DC AMIA 2003 Symposium Proceedings; 2003, 106-109.

37. Linstone HA, Turoff M: The Delphi Method, Techniques and Applications. Edited by: Linstone HA, Turoff M 2002 [http://www.is.njit.edu/pubs/ delphibook/, [Accessed 28 November 2009].

38. Brooks KW: Delphi technique: Expanding applications. North Central Association Quarterly 1979, 54(3):377-385.

39. Altschuld JW: Delphi technique. Lecture: evaluation methods: Principles of needs assessment I/ Department of Educational Services and Research. Columbus: The Ohio State University; 1993.

40. BHF: Guidelines on the promotion of physical activity with older people British Heart Foundation. London; 2007.

41. Fink A, Kosecoff J, Chassin M, Brook RH: Consensus methods: Characteristics and guidelines for use. American Journal of Public Health 1984, 74:979-983.

42. Powell C: The Delphi technique: Myths and realities. Journal of Advanced Nursing 2003, 41:376-382.

43. Sumsion T: The Delphi technique: an adaptive research tool. British Journal of Occupational Therapy 1998, 61(4):153-156.

44. Murphy MK, Black NA, Lamping DL, McKee CM, Sanderson CF, Askham J, Marteau T: Consensus development methods and their use in clinical guideline development. Health Technology Assessment 1998, 2(3):1-88.

45. Dawes J: Do data characteristics change according to the number of scale points used? An experiment using 5-point, 7-point and 10-point scales. International Journal of Market Research 2007, 50(1):61-77.

46. Kelly CM, Hoehner CM, Baker EA, Ramirez LKB, Brownson RC: Promoting physical activity in communities: Approaches for successful evaluation of programs and policies. Evaluation and Program Planning 2006, 29:280-292. 
47. Schmid TL, Librett J, Neiman A, Pratt M, Salmon A: A framework for evaluating community-based physical activity promotion programmes in Latin America. Promot Educ 2006, 13(2):112-118.

48. AACVPR: Guidelines for Cardiac Rehabilitation and Secondary Prevention Programs. 4 edition. American Association of Cardiovascular and Pulmonary Rehabilitation. Champaigh, IL.: Human Kinetics; 2004.

49. Anyamele SC: Implementing quality management in the University: The role of leadership in Finnish Universities. Higher Education in Europe 2005, 30(3-4):357-369.

50. Taffinder P: The New Leaders: Achieving Corporate Transformation through Dynamic Leadership London: Kogan Page; 1995.

51. Dale BG: Managing Quality. 4 edition. Malden: Blackwell Publishing Ltd; 2003.

52. Gill R: Theory and practice of leadership London: SAGE; 2006

53. Oakland JS, Tanner S, Gadd K: Best practice in business excellence. Total Quality Management 2002, 13(8):1125-1139.

54. Waldman DA, Lituchy T, Gopalakrishnan M, Laframboise K, Galperin B, Kaltsounakis Z: A qualitative analysis of leadership and quality improvement. Leadership Quarterly 1998, 9:177-202.

55. Vala J, Torres A, Ramos A: Inquérito Social Europeu 2006: resultados globais. Lisboa: ICS-UL e ISCTE; 2008.

56. ACSM: Physical activity programs and behavior counseling in older adult populations. Med Sci Sports Exerc 2004, 36(11):1997-2003.

57. Kotter JP: What leaders really do. Harv Bus Rev 1990, 68(3):103-111.

58. EFQM: The Fundamental Concepts of Excellence Brussels: European Foundation for Quality Management; 2003.

59. Nabitz U, Schramade M, Schippers G: Evaluating treatment process redesign by applying the EFQM Excellence Model. Int I Qual Health Care 2006, 18(5):336-345.

60. Soares P, Serôdio-Fernandes A, Machado-Santos C: MEDE: Modelo da Excelência no Desporto - gestão da qualidade e da excelência na gestão do desporto Vila Nova de Gaia: APOGESD; 2007.

61. CDC: Physical Activity Evaluation Handbook Centers for Disease Control and Prevention. Atlanta; 2002.

62. NHS: Exercise Referral Systems: A National Quality Assurance Framework. Health Do. England; 2001.

63. Bartholomew LK, Parcel GS, Kok G, Gottlieb NH: Intervention mapping: designing theory-and evidence-based health promotion programs New York: McGraw-Hill; 2000.

64. Scott F, Young A, Dinan-Young S, Harding M, Lewis S, Fisken S: Expert Survey on Physical Activity Programmes and Physical Activity Promotion Strategies for Older People - Cross-National Report. European Network of Action on Aging and Physical Activity; 2008 [http://www.eunaapa.org/], [Accessed 23 January 2010].

65. EFQM: The EFQM Framework for Managing External Resources: Driving performance and growth through excellence in managing external resources Brussels: European Foundation for Quality Management; 2006.

66. Balady GJ, Chaitman B, Driscoll D, Foster C, Froelicher E, Gordon N, Pate R, Rippe J, Bazzarre T: Recommendations for cardiovascular screening, staffing, and emergency policies at health/fitness facilities. Circulation 1998, 97(22):2283-2293.

67. WHO: Report of the World Health Organization. Active ageing: a policy framework. Aging Male 2002, 5(1):1-37.

68. Stewart AL, Verboncoeur CJ, McLellan BY, Gillis DE, Rush S, Mills KM, King AC, Ritter P, Brown BW Jr, Bortz WM: Physical activity outcomes of CHAMPS II: a physical activity promotion program for older adults. $J$ Gerontol A Biol Sci Med Sci 2001, 56(8):M465-470

69. Thurston M, Green K: Adherence to exercise in later life: how can exercise on prescription programmes be made more effective? Health Promot Int 2004, 19(3):379-387.

70. Oakland JS, Beardmore D: Best Practice Customer Service. Total Quality Management 1995, 6(2):135-148.

\section{doi:10.1186/1479-5868-8-104}

Cite this article as: Marques et al:: A proposed adaptation of the European Foundation for Quality Management Excellence Model to physical activity programmes for the elderly - development of a quality self-assessment tool using a modified Delphi process. International Journal of Behavioral Nutrition and Physical Activity 2011 8:104.

\section{Submit your next manuscript to BioMed Central and take full advantage of:}

- Convenient online submission

- Thorough peer review

- No space constraints or color figure charges

- Immediate publication on acceptance

- Inclusion in PubMed, CAS, Scopus and Google Scholar

- Research which is freely available for redistribution

Submit your manuscript at www.biomedcentral.com/submit
Biomed Central 